\title{
A fragmentação do mito da democracia racial e a dimensão pedagógica do cinema negro
}

\author{
Celso Luiz Prudente \\ Universidade Federal do Mato Grosso - UFMT, Brasil
}

DOI: https://doi.org/10.31492/2184-2043.RILP2020.38/pp.157-171

\begin{abstract}
Resumo
Este artigo trata a fragmentação do mito da democracia racial, cuja sociedade brasileira monocultural foi vista como um paraíso de laboratório racial, para os países multirraciais. O Movimento Negro Unificado - MNU lutou contra o racismo, a violência policial e a ditadura militar, fragmentando o mito da democracia racial brasileira. Os ativistas negros se identificaram com o cinema novo, de Glauber Rocha, que adotou o negro como referencial estético. Glauber criou também o cinema negro, sendo o cinema das minorias vulneráveis, no qual a imagem do ibero-ásio-afro-amerindio fez uma luta ontológica contra a hegemonia imagética do euro-hétero-macho-autoritário sua euroheteronormatividade, que foi o sentido da eurocolonização. Na dimensão pedagógica do cinema negro as minorias desenvolveram a construção da imagem de afirmação positiva, ensinando ao anacronismo excludente como ela é, e deve ser tratada, na sociedade de contemporaneidade inclusiva.

Palavras-chave: dimensão pedagógica do cinema negro; ibero-ásio-afro-ameríndio; euro-hétero-macho-autoritário; euroheteronormatividade.

Abstract

This article deals with fragmentation of the myth of racial democracy, whose monocultural Brazilian society was seen as a racial laboratory paradise for multiracial countries. The so-called "Movimento Negro Unificado" (or Unified Black Movement) fought against racism, police violence and military dictatorship, fragmenting the myth of Brazilian racial democracy. Black activists identified with the filmmaker Glauber Rocha's "Cinema Novo" movement, which adopted black people as the aesthetic framework. Glauber also created the black cinema in Brazil, being the cinema of the vulnerable minorities, in which the image of the Ibero-Asio-Afro-Amerindian made an ontological struggle against the imaginary hegemony of the Euro-hetero-male-authoritarian its Euro-heteronormativity, which was the sense of the Euro colonization. In the pedagogical dimension of black cinema, minorities have developed the construction of the positive affirmation image, teaching exclusionary anachronism as it is, and should be treated, in an inclusive contemporary society.
\end{abstract}

Keywords: pedagogical dimension of black cinema; ibero-asio-afro-amerindian; euro-straight-male-authoritarian; euroheteronormativity.

Neste artigo mostro que raça e cor se confundem apontando frágil mobilidade no Brasil, onde a desigualdade social foi configurada por uma possível espécie de relação de bicoloridade, demandada por relações de contradições sociorraciais. Estas contradições sugeriram as possíveis condições de privilégios, entre cores raciais diferentes. Observei que esta constatação foi fatal ao discurso oficial, que teve ressonância internacional, na medida em que se considerava o Brasil, como laboratório do paraíso racial, em sociedade multirracial, Prudente (2019a). De tal 
sorte o negroide de cor preta se traduziu em condição social, sendo assim a cor da pobreza e do seu desdobramento. Isto, implicando-o na marginalização dos bens socialmente válidos.

Considero no artigo como bens socialmente válidos: saúde, educação, habitação e lazer de qualidade, que formaram prováveis marcas simbólicas, de status social, em que o ator faz questão de ser observado e implicado nele, como são os casos das filas, de cinema e de restaurante, que são privilegiados/badalados, nos finais, de semana. Lugares em que o negro com raras exceções estão presentes. Razões pelas quais são chamados lugares de brancos.

Este quadro mostrou, por seu turno, um paradoxal domínio étnico-racial do branco em relação aos bens socialmente validos em voga. Fenômeno que se estabeleceu como um processo de darwinismo social, cuja condição de possuidor privilegiado do eurodescendente se deu somente pela situação de (des) possuído e de (des) prestigiado do afrodescendente. Nos dias de hoje se observou, sobretudo que os negros em razão do dilema sócio racial, são mais vulneráveis a violência com desdobramentos dos homicídios, como segue:

Em 2017, 75,5\% das vítimas de homicídios foram indivíduos negros (definidos aqui como a soma de indivíduos pretos ou pardos, segundo a classificação do IBGE, utilizada também pelo SIM), sendo que a taxa de homicídios por 100 mil negros foi de 43,1, ao passo que a taxa de não negros (brancos, amarelos e indígenas) foi de 16,0 . Ou seja, proporcionalmente às respectivas populações, para cada indivíduo não negro que sofreu homicídio em 2017, aproximadamente, 2,7 negros foram mortos. Atlas da violência (IPEA, 2019).

A população brasileira vive uma crise de identidade racial, sugerindo uma frágil consciência racial, mesmo sendo inegavelmente miscigenada se viu pelo ideal branco europeu. Como observa também o cineasta e pesquisador Joel Zito, "sendo um dos seus corolários o desejo de euro-norte-americanização" Araújo (2004, p. 25). Percebi que o índio, só se aceitava como índio quando foi chamado de negro. Aceitava-se somente português, na medida em que foi chamada de índio. Isto é um comportamento patológico, no qual o brasileiro detentor das matrizes formadoras: ibérica, asiática, africana e ameríndia, que formaram a miscigenação brasileira na amálgama, caracterizada na imagem do ibero-ásio-afro-ameríndio, Prudente (2018). Considerei isto como um processo de autonegação racial de ancestro paternidade, sugerido neste artigo contra a parte afrodescendente da família, ou seja, atingindo os avós e os pais negros.

Considero que, nos países poliétnico de economia dependente, como é o caso específico da sociedade brasileira, o modo de produção determinou a localização 
social, pautando possivelmente a seleção racial. Esta situação indicou as relações de privilégios, sociorracial.

Quanto mais se aproxima da analogia com a feição da colonização, tanto mais se encontra próximo das relações sócio-privilegiadas, Prudente (2018). Segundo Marx e Engels "[a burguesia] cria o mundo a sua imagem e semelhança” Marx e Engels, (1848, p. 14). A colonização foi um projeto europeu, no qual o ibérico exerceu protagonismo, mas, sendo concomitantemente objeto da colonização, cujo resultado concorreu ao acúmulo de riqueza à formação da Revolução Industrial, que foi europeia de natureza inglesa e não ibérica de caráter portuguesa.

Por outro lado o branco enquanto elemento sociorracial foi selecionado, historicamente, à exclusividade de participação nos bens socialmente válidos; formando uma separação racial de caráter estrutural, que concorreu para a formação de um provável tipo de apartheid a brasileira. Esta segregação racial jamais foi admitida, porém sempre permitida, formando um racismo tipicamente brasileiro, no qual se tentou impor o fundo da sociedade, a periferia social, como lugar de negro. $\mathrm{O}$ afrodescendente foi vítima da tentativa de redução à condição de perieco.

Como vítima da condição de periférico o negro foi colocado na franja da sociedade, sendo marginalizado no mercado de trabalho. Na atualidade a função social das empresas tem sido frágil, considerando-se que as maiores empresas brasileiras não são sensíveis às políticas afirmativas para combater a desigualdade sociorracial nas empresas:

\footnotetext{
Convém lembrar, além disso, a propósito das ações afirmativas, que só 14 de 117 empresas dizem possuir atualmente alguma política visando à promoção da igualdade de oportunidades entre negros e não negros, e que apenas uma estabelece metas para ampliar a presença de negros em cargos de direção e gerência. (Instituto Ethos, 2016).
}

Isto desarticulou o negro da integração social impossibilitando estruturalmente de participar dos bens socialmente válidos, que se constituíram, deste modo, em um lugar de branco.

Onde se falava que não existia racismo, tais como: nas escolas, nas universidades, nos hospitais, nos consultórios médicos, nos condomínios habitacionais, nos clubes e nos restaurantes, porém não se observava a presença de negro. Os afrodescendentes se constatavam somente em trabalhos (des) qualificados, subempregos ou na condição, de mãos sujas para oprimir os próprios negros, quando se aproximavam dos espaços urbanos saneados, mostrando privilégio social, que também se traduziu em condição racial, como lugares reservado para os brancos.

A segregação racial, entre nós, é sistemática característica do racismo estrutural, que impregnou as relações sociais, formando um tipo de apartheid a 
brasileira, que foi chamado de democracia racial. Isto se constituiu em mitológica política, que buscou legitimar o racismo, disfarçado de harmonia considerando que este racismo estrutural manteve relações de aproximação entre negros e brancos, isto teve origem na relação de aproximação do escravo da casa grande com o senhor de engenho que o mantinha na condição de escravo chamando-o de afilhado. Este fenômeno concorre em favor de uma solércia de satisfação do oprimido negro em gratidão a cordialidade da opressão branca, Holanda (1999). Para a pesquisadora Lilia Schwarcz, "a cordialidade é entendida por Sérgio Buarque de Holanda como intimidade, horror à distância etc.; não quer dizer nem polidez nem civilidade" Schwarcz (2008, p. 146). O Brasil tem o costume do racismo de tapinhas nas costas onde se imputa ao reclamante do racismo a condição de chato, considerando que uma piada que desconsidera a questão de gênero, de raça e de etnia, como sendo algo palatável que aproxima as pessoas quebrando a formalidade.

Um grupo que foi constituído por jovens negros, formou o MNU - Movimento Negro Unificado, que foi um movimento juvenil de inspiração marxista, fundado pelos ativistas: Milton Barbosa, Rafael Pinto, Hamilton Cardoso, Neusa Maria Pereira, Wilson Prudente e Celso Prudente.

Foram fundamentais as presenças solidarias que se mostraram constantes dos importantes intelectuais, tais como: o esteta Abdias do Nascimento, o sociólogo Clovis Moura, a antropóloga Lélia González e o poeta Eduardo de Oliveira. Estes intelectuais negros gozavam de prestigiosos reconhecimentos, junto a setores democráticos e progressistas, da sociedade organizada na luta democrática contra o autoritarismo militar.

Embora fosse de inspiração socialista, o grupo sofreu resistência das esquerdas, que entenderam, na época, que a questão racial dividia as lutas de classes. Esta resistência não se mostrou suficiente para desarticular a militância em voga, que em 07 de julho de 1978, fez uma manifestação nas escadarias do Teatro Municipal de São Paulo. Este protesto racial apresentou como bandeira, as lutas: contra a ditadura militar e contra a violência policial. Demonstrando a compreensão deste grupo insurreto, que a marginalização racial sofrida pela juventude negra foi expressão do capitalismo selvagem. Para o discernimento político dos jovens militantes do MNU, tratava-se de um sistema econômico responsável pela produção da miséria, que por sua vez concorria em favor do racismo contra os negros.

$\mathrm{O}$ ato público foi objeto de histórica repercussão nacional e internacional, que fragmentou o mito da democracia racial, revelando incomensurável marginalização do jovem negro, no processo escolar e no mercado de trabalho, sobrando-lhe 
por decorrência desta miserabilidade a perseguição policial. Esta manifestação do MNU foi talvez um, dos atos políticos mais caros, do governo militar. Pois, o militarismo encontrou no mito da democracia racial o seu diferencial de positividade internacional. A denúncia da marginalização dos jovens negros foi motivada por um ideal eurocêntrico contra o jovem de origem africana. Isto sugere um comportamento esquizofrênico, no qual o brasileiro com origem nas matrizes formadoras, tais como: a ibérica, a asiática, a africana e a ameríndia, não se aceitava com imagem de formação miscigênica do ibero-ásio-afro-ameríndio Oliveira \& Prudente (2017).

Isto chamou atenção para o surgimento de uma possível espécie de ancestrocídio simbólico, dos avós e dos pais, ibero-ásio-afro-ameriníos, sobretudo, os africanos. Entendo que este genocídio simbólico levantado neste artigo são narrativas esquizofrênicas, que constituíram em partes, como presenças emergenciais, nas reuniões, que aconteceram nas salas dos amigos eurodescendentes, tipicamente de classe média, que são vistos como "importantes", apresentando-lhe, com patológicos destaques de várias qualidades para tentar justificá-lo na tal sala, da possível lugaridade de cor social, considerei nesta reflexão como o lugar de branco, sendo um espaço social propício aos implicados nos bens socialmente válidos.

Nesta ambiência sociorracial com domínio de ideal de cor branca, cujo miscigenado tentou demasiadamente falar dos pais e dos avós de ascendência europeia, como forma de provável anulação homicida da descendência, ibérica, asiática, africana e ameríndia, sobretudo na tentativa de anular a descendência negra. Isto se deu com um silêncio anulador, que caracterizou uma espécie de automutilação racial da parte negra do miscigenado. Esta situação resultou na construção da taxionomia multicor do tentame de depreciação étnico-racial da diversidade cultural dos povos estranhos ao nomos caucasianos eurocidentais.

Este ancestrocídio do negro, que trato, neste artigo, como sendo praticado pelo miscigenado teve teleologia escatológica, cujo miscigenado tentasse um salvacionismo, que foi dado pelo silêncio. Isto determinou um silêncio que escondeu a descendência negra.

Entendo que esta situação ilustra a negação das cores nas relações étnico-raciais, de tal sorte que: a) o branco ibérico, isto é o português foi considerado, o “burro sem rabo". Avelar (2018 pp. 63-65); b) amarelo asiático, ou seja, o japonês foi tratado como o "pênis pequeno", o "pau pequeno que amarelou na hora $\mathrm{h}$ "; c) o vermelho ameríndio foi apontado na condição "falso", "perigo vermelho", "primitivo" e "selvagem contra o progresso" e; d) o preto negro africano foi tachado de "boçal", "engraçado" e "sensualizado." Estes estereótipos foram dados 
aos povos, de culturas estranhas aos nomos, eurocidental, são estereótipos nas relações étnico-raciais, que concorreram à negação multicultural, em proveito do poder do homem caucasiano europeu que foi caracterizado aqui na configuração da hegemonia imagética euro-hétero-macho-autoritário, com sua dominação nas relações étnico-raciais, com a política de escolaridade monocultural, do branco europeu.

Isto se fez na condição do preconceito racial, mas definitivamente, não aceitando a marca de racista. Esta esquizofrenia encontrou sua gênese no escravismo brasileiro se mostrando atípico, na medida em que o senhor escravizava o próprio filho, estando, porém impregnada na postura de bom moço, do "homem cordial", Holanda (1999, p. 107), que se tornou um imaginário brasileiro, de dominação etnocêntrica. Tratando de um fenômeno no qual o senhor de escravo foi um homem bom, e que as relações sociorraciais são boas e harmônicas, sugerindo que os negros aceitavam a marginalização absoluta que lhes impuseram por meio do mito da superioridade racial do branco, como algo que implicava na inferioridade do negro. Esta ação mitológica teve como base a solércia da escravidão, que aqui foi apresentada como única, impondo ao escravizado a condição de inferior.

A origem, desta contradição étnico-racial, está na persistência da essência eurocolonial, no qual o estado teve um ideal monocultural, concorrendo em proveito do eurocentrismo. Este estado brasileiro ocidental centenário nasceu, com efeito, antes da nação, sendo estruturalmente contra a diversidade multicultural com formação, ibérica, asiática, africana e ameríndia sendo por isto concorrente a axiologia eurocolonial, que negava todos os nomos estranhos às expressões, que são de caráter caucasiano europeu.

Observei que no Brasil, o cinema nasceu em um processo das relações étnico-raciais da imagem do ibero-ásio-afro-amerindio. A primeira fase da trajetória cinematográfica começou com a tentativa de negação do ruralismo pela implacável imposição do ideal de progresso positivista, Prudente (2019b). Isto foi uma articulação política do urbano industrialismo, que foi defendido na política getulista.

A Revolução Tecnológica se encontra nos estágios da inteligência e da vida artificial, na qual a informação ocupa o centro substancial desta era, tal como a máquina foi à centralidade essencial dos tempos industriais. Considero a representação como um fator referencial, em que percebo que as relações abstratas da representação se tornaram mais importante que as relações objetivas da realidade, percebendo também que a objetividade da realidade tem consubstancialidade histórica. É pertinente falar no dualismo, - proletariado versus burguesia, próprio do industrialismo, na era da informação, estou sugerindo que as lutas de classes se traduziram em lutas de minorias vulneráveis, em relação à euroheteronormatividade, que se projetaram em lutas de imagens. 


\section{O cinema negro como arte de afirmação ontológica do afrodescendente}

\section{Chanchada}

A Chanchada mostrava inequívoca obediência aos interesses externo, sendo um cinema em proveito do colonialismo cultural. Foi chamada de cinema dos Grandes Studios, em razão do compromisso com a indústria, (Ramos, 1960; Carvalho \& Domingues, 2017; Prudente 2019b). Esta tendência cinematográfica teve provavelmente um papel de instrumento das relações étnico-raciais eurocêntrica, que atendeu por isto o industrialismo positivista visto na política getulista. Nesta filmografia o camponês expressou o estágio rural do índio, e foi tratado como anti-herói, na condição de avesso ao progresso. Esta tendência cinematográfica sugere a negação epistêmica da imagem do ibero-ásio-afro-amerindio, mostrando a herança indígena do camponês com traços de indolência, com base no estereótipo de inculto e de incauto, construído no personagem do Jeca Tatu, que foi mostrado como estranho ao desenvolvimento (Palma, 2009; Prudente, 2019b).

Chamo atenção para a competência inequívoca da interpretação do comediante Mazzaropi, que concorreu ainda mais à tentativa de impor no camponês a pecha de inepto. Foi construída, portanto uma espécie de manipulação, colocando o descendente de índio como elemento essencial ao ruralismo, apontando assim a amerindidade como referência rural; sendo o ruralismo, algo de natureza atrasada à visão eurocêntrica, que indicou pelo estereotipo imagético de anti-herói do Jeca Tatu, como avesso ao progresso em decorrência da descendência ameríndia (Palma, 2009; Prudente, 2019b).

Isto se fez para desarticular o ideal rural, que foi construído no comportamento estranho ao progresso, dado por meio do estereótipo de boçalidade impregnado no personagem do Jeca Tatu, cujo comportamento foi contrário ao desenvolvimento. Articulando assim um contra ponto com o industrialismo, enquanto expressão do progresso, que encontrou no branco europeu, o tipo ideal, negando a imagem do ibero-ásio-afro-ameríndio, em razão da teluricidade rural própria da descendência indígena.

Esta ação eurocêntrica fez da Chanchada um instrumento de negação dos traços epistêmicos do ameríndio, que se deu conjugado a invisibilidade da presença física do afrodescendente. Isto por sua vez foi feito concomitante a apropriação da axiologia afro-brasileira. Este fenômeno se estabeleceu mediante a negação do corpo negro. Esta situação de desarticulação sociorracial de cor preta foi revelada concomitante a inegável tentativa de apropriação da alma negra. Percebi que esta usurpação axiológica foi feita pela hegemonia racial da cor branca europeia. A apropriação cultural da alma negra foi traduzida na música e na dança, que estiveram presentes na estrutura estética da própria tendência em questão. Esta situação 
foi feita pela hegemonia imagética do branco, que com invisibilidade concorreu pela negação do corpo da africanidade.

\section{Cinema novo}

A efervescência sociocultural da década de setenta, como parte da ascensão internacional dos movimentos de massas, impactou as relações étnico-raciais do negro brasileiro. As marchas pelos direitos civis nos EUA lideradas pelo reverendo Martim Luter King e as descolonizações africanas revolucionárias, de orientação marxista, influenciaram a juventude negra brasileira. Esta confluência política aconteceu no período de surgimento do cinema negro, cujos jovens afro-brasileiros demonstraram inequívoca identidade política e cultural, africana e afrodiaspórica. Ensejo no qual o cineasta baiano Glauber Rocha criou a tendência cinemanovista, que privilegiou o negro brasileiro. Criação que se fez concomitantemente ao reconhecimento de principal ideólogo e precursor do cinema novo, que foi a origem do cinema negro (Carvalho \& Domingues, 2017; Prudente, 2019a).

O cinema novo foi uma tendência cinematográfica, que se ocupou tematicamente com a realidade brasileira e a cultura popular, na perspectiva da transformação social. Este comportamento foi definitivamente uma crítica a Chanchada, que tratava a cultura brasileira na perspectiva folclórica. Pois, não se preocupava com as contradições sociais.

A sintaxe cinema novista teve influência marxista em uma demonstração inequívoca da contradição sociobicolor, de conflito preto e branco, na qual o negro representava o proletariado e seu desdobramento da relação de pobreza, e o branco expressava a burguesia e sua decorrência de poder, Gerber (1977). A pirâmide social brasileira sugere uma analogia com uma formula química, sendo assim: "clara em cima e na medida em que se desce vai escurecendo", Prudente (2019b, p.70).

O nascimento do cinema novismo aconteceu em 1955, com o filme "Rio 40 Graus", de Nelson Pereira dos Santos, Ramos (1960). A película apresentou um enredo, cuja ambiência foi o negro e a sua cultura. Assim que Glauber Rocha assistiu ao filme vaticinou o nascimento do cinema novo, Ramos (1960). Glauber mostrou profunda identidade com a realização em voga, chamando Nelson Pereira, para montar o "Barravento", que foi o seu primeiro filme de longa metragem. Esta realização glauberiana foi também desenvolvida com tema da africanidade.

O filme "Cinco vezes favela" foi considerado manifesto do cinema novo, que foi realizado por jovens militantes de esquerda, que "eram filiados ou simpatizantes do Partido Comunista do Brasil- PCB, (...) com passagem pelo Centro Popular 
de Cultura - CPC da União Nacional dos Estudantes - UNE (...) comungavam da crença (...) da gramática do engajamento" Carvalho e Domingues (2017, p.2) estes jovens cineastas realizaram o filme "Cinco Vezes Favela", que foi uma reunião de cinco curtas metragens, os quais trataram também do negro e sua cultura. Isto pareceu contribuir para reforçar ainda mais o discernimento, no qual o cinema novo encontrou no negro a sua referência.

A temática da africanidade foi elemento estrutural na estética da tendência em questão. Isto mostrou uma identidade com a juventude negra, que se viu representada no cinema, que foi uma cinematografia de reflexão crítica contra a dominação social de caráter burguês. Esta postura política foi fundamental para aproximação dos jovens negros de esquerda com a irreverência cine marxista, da realização cinema novista, sobretudo o pensamento de Glauber Rocha, que foi o principal ideólogo do cinema novo.

No cinema novo o negro se configurou como referencial estético. Por outro lado, no cinema negro o afrodescendente se revelou reescrevendo criticamente sua história com a câmara na mão, e ocupou assim a condição de sujeito histórico, Prudente (2019a).

\section{Cinema negro}

Considerei, nesta reflexão, que no cinema novo o negro foi referência estética, sobretudo na cinematografia glauberiana. Mas foi o próprio Glauber Rocha, que criou o cinema negro brasileiro. Sendo ele baiano com fenótipo ibero-ásio-afro-ameríndio, com um irreverente discurso de volta as origens, como retomada da teluricidade africana, na luta contra o colonialismo. Isto se fez somado a sua visão de realização de três continentes, Prudente (2019b).

Em 1970, este realizador fez a película, intitulada: "Leão de Sete Cabeças", uma produção franco-italiano, que foi filmado no Congo de Brazzaville, Cardoso (2007). Percebi que o filme sugere uma atemporalidade, cujos heróis afro-ameríndios, com o personagem Zumbi sugerindo o Zumbi dos Palmares, e o personagem Pablo inspirado no Ernesto Guevara (Che Guevara), que viveram em tempos de teluricidade afro-latinos diferentes, unindo-se na África, para combater o colonialismo. No pensamento glauberiano a colonização foi à gênese da dominação burguesa. O dramaturgo Aimé Césaire apontou o problema da decadência colonial, indicando-a como um dos maiores problemas da civilização ocidental, como segue: 
incapaz de resolver os dois problemas maiores aos quais a sua existência deu origem: o problema do proletariado, e o problema colonial (...). Césaire, (1971, pp. 5-6)

Este autor baiano com uma estética original rompeu com a própria forma fílmico-cinematográfica do filme "O dragão da maldade contra o Santo guerreiro", que the consagrou como melhor filme em 1968, no Festival de Cannes. Usou da técnica de efeito do distanciamento brechtiano, somado a influência do cinema reflexivo Jean Luc Godard, Cardoso (2007), com olhar de subjacência na polissemia procissional, caminhando revolucionariamente para frente, que se fez presente no imaginário da irreverente arte revolucionaria. Como observei na canção de Geraldo Vandré considerado hino revolucionário brasileiro: "Caminhando e cantando e seguindo a canção. Somos todos iguais braços dados ou não. Nas escolas nas ruas campos e construções. Caminhando e cantando e seguindo a canção".

O filme sugeriu a vitória da união dialética do conhecimento revolucionário, como um indicativo da utopia da Mãe África, como lugar ideal das relações comunais, que formaram a raiz do socialismo. Demonstro que este discurso glauberiano, de volta as origens influenciou a juventude negra fundadora do MNU, que fez uma revisão crítica da história. Razão pela qual alguns destes jovens militantes seguiram a postura glauberiana, indo à África reescrever a história com câmara cinematográfica. Em 1979, ainda jovem, o militante negro Ari Cândido, seguindo os passos de Glauber Rocha, foi à Etiópia, onde realizou o filme "Por que a Eritréia?", O Menelick, (2014), cujo enredo tratava da guerra civil deste país africano.

Ocupou com isto o papel de sujeito, aquele que se torna autor da sua própria historia. Acredito que foi esta a principal contribuição da filmografia em voga, que levou o negro para além da importante posição de referência estética do cinema novo, conquistando assim o papel de sujeito do cinema, que é a condição do realizador. É ilustrativo lembrar que na linguagem teatral o ator mostrou domínio, na linguagem televisiva o domínio ficou com o redator e na linguagem cinematográfica o realizador é o detentor do domínio.

O cinema negro se tornou o cinema das minorias vulneráveis, considerando a dimensão pedagógica do cinema negro, contribuindo para construção da imagem de afirmação positiva, que foi aviltada pela hegemonia imagética da verticalidade do euro-hétero-macho-autoritário e a sua euroheteronormatividade, Prudente (2019a). Para o pesquisador português Morais-Alexandre:

“[A] investigação (...) de Celso Prudente possibilitou novos cruzamentos, sobretudo a percepção de memorização do "ibero-ásio-afro-ameríndio" pelo "euro-hétero-macho-autoritário", permitindo sem 
dúvida o cinema negro, mas não só, como se verá, resgatar uma imagem positiva do não dominante" (Morais-Alexandre, 2019, p.140).

Formando a essência do tentame da fragmentação epistêmica da imagem do ibero-ásio-afro-ameríndio, enquanto minoria diante da dominação eurocolonial caucasiana.

\section{A dimensão pedagógica do cinema negro}

O discernimento da categoria conceitual, de dimensão pedagógica de cinema negro, que se deu no campo da educação das relações étnico-cinematográficas da africanidade, pareceu necessário para compreender o cinema além dos domínios: da comunicação, da arte e da difusão de ideias, Prudente $\left(2019^{a} \&\right.$ b). Nesta reflexão, o cinema como forma de conhecimento, prenunciou a era da informação, que foi por seu turno a era do conhecimento, porque conhecimento também o foi (Duarte, 2002; Prudente, 2019a \& b).

Observo que outras modalidades artísticas também anteciparam a era do conhecimento, por meio da ficção científica. Porém nenhuma modalidade artística fez o prenúncio desta era com perfeccionismo cinematográfico. Pois nele se deu com movimento Deleuze (1983), que foi conjugada com o tridimensional, permitindo uma mimética mais próxima do real.

O conhecimento é uma condição humana, que encontra no pensamento a sua expressão mais nobre. $\mathrm{O}$ cinema sugere também formulação de pensamento, cuja imagem para o realizador se constitui em um conceito. O pesquisador Rogério Almeida escreve: "assim como a matéria do filósofo é o conceito a do cineasta é a imagem" Almeida (2017, p. 15). O debate com o realizador não ficou restrito à filotecnia, comportando com conforto o pensador. Como percebido em Deleuze: “(...) autores de cinema nos pareceram confrontáveis não apenas com pintores, arquitetos, músicos, mas também com pensadores. Eles pensam com imagens-movimento e com imagens-tempo" Deleuze (1985, p.8). A compreensão de imagem-movimento sugerida em Deleuze (1983) foi sugestiva para se pensar o movimento do fotograma como processo histórico, que reflete a emergência social do cinema como produção de sentido, Duarte (2002); “... o plano das imagens-movimento, um corte móvel de um Todo que muda, isto é, de uma duração, de um devir universal" (Deleuze, 1983, p. 92).

Trago neste artigo a sugestão de humanabilidade que decorre da provável aproximação da dimensão da linguagem do cinema com valores que são da existencialidade humana, que são diferentes de outras artes. O cinema epistêmico se revela também na psicologia, como se vê nomeadamente a percepção no cinema, como observa em Walter Benjamin: 
O cinema em toda sua amplitude da percepção óptica, e agora também acústica, teve como consequência um aprofundamento semelhante a percepção. O reverso deste facto reside em que os desempenhos num filme são analisáveis mais exactamente e sob mais ponto de vista do que os desempenhos apresentados num quadro ou no palco. No que diz respeito à pintura, o que permite uma melhor análise do desempenho apresentado num filme é a informação mais exata sobre as situações que o cinema faculta. Relativamente ao palco, a maior capacidade de análise do desempenho apresentado no filme é condicionada pelo fato deste ser mais isolável nos seus elementos constituintes. O significado principal desta circunstância reside na tendência para promover a penetração mútua entre arte e ciência. (Benjamin, 1955, pp.15-16).

Assim Benjamin (1955) também percebeu a possibilidade do cinema como um elemento epistemológico. Isto provavelmente contribui para compreensão de uma humanidade que permite uma amplitude existencial, possibilitando o questionamento das relações estabelecidas.

$\mathrm{Na}$ mesma lógica Agamben discerniu o cinema como um elemento de resistência, que se dá numa existencialidade de demanda religiosa, sugerindo que a criação é uma des-criação, “(...) Todo ato de criação é também um ato de pensamento, e um ato de pensamento é um ato criativo, pois o pensamento define-se antes de tudo pela sua capacidade de des-criar o real", Agamben (1998, pp.6576), esta observação permite compreender o cinema como transformador e revolucionário.

Isto é sugestivo para inferência, na qual percebi no cinema uma possível espécie de medida humana, que será sugerida como humanabilidade. Fenômeno sugestivo para se compreender o cinema como forma de conhecimento, Duarte (2002). Fez-se assim como elemento de sentido essencial da era do conhecimento, "tornando-se a partir da dimensão pedagógica do cinema negro o cinema das minorias, na medida em que conhecimento e preconceito são antitéticos", Prudente (2019b, p. 75).

O cinema negro se tornou com isto cinema das minorias, tais como: negro, mulher, homossexual, deficiente e outros, que são objetos do tentame de fragmentação dos traços epistemológicos, feito pelos estereótipos impostos pelos meios de comunicação de massas, que foram dados pelo poder autoritário da imagem do homem branco europeu e sua euroheteronormatividade, que foi a razão da eurocolonização. Foi na dimensão pedagógica do cinema negro, que a minoria vulnerável ensinou na luta ontológica, como sociedade monocultural branca impregnada do processo anacrônico excludente, como ela é, e como deve ser tratada. Isto como elemento imperativo para sociedade excludente superar seu anacronismo, entrando no trilho da contemporaneidade inclusiva.

Isto sugere um compromisso de consciência do respeito à diversidade, das relações dinâmicas de natureza poliétnica, que se revelou na inequívoca configuração multicor próprio da imagem dinâmica, de horizontalidade democrática do 
ibero-ásio-afro-ameríndio e das minorias como um todo, Prudente (2019a \& b). Conclui que isto se deu no processo ontológico de construção da imagem de afirmação positiva do negro, enquanto minoria, construindo sua imagem de afirmação positiva, ensinando, dialeticamente, como deve ser tratada em uma sociedade democrática, com base na inclusão.

\section{Referências}

Agamben, Giorgio. O cinema de Guy Debord. Território de filosofia. Aurora Baêta. 26 de maio de 2014. Disponível em: https://territoriosdefilosofia.wordpress.com/2014/05/26/o-cinema-de-guy-debord-giorgio-agamben/ Acesso em: 01 maio 2020. Texto originalmente publicado em: Agamben, Giorgio. L. in: Image et mémoire, Hoëbeke, 1998, pp. 65-76.

Almeida, Rogério de. Cinema e educação: fundamentos e perspectivas. Educ. rev. [online]. 2017, vol.33, e153836. Epub Apr 03, 2017. ISSN 0102- 4698. https://doi.org/10.1590/01024698153836.

Atlas da violência 2019. Organizadores: Instituto de Pesquisa Econômica Aplicada; Fórum Brasileiro de Segurança Pública. Brasília: Rio de Janeiro: São Paulo: Instituto de Pesquisa Econômica Aplicada; Fórum Brasileiro de Segurança Pública. ISBN 978-85-67450-14-. Disponível em: <http://www.forumseguranca.org.br/wp-content/uploads/2019/06/Atlas-da-Violencia-2019_ 05jun_versão-coletiva.pdf $>$ Acesso em 12 de set. 2019.

Araújo, Joel Zito. A Negação do Brasil: o negro na telenovela brasileira. $2^{\mathrm{a}}$ ed. Senac. São Paulo. 2004.

Avelar, Juarez. 50 contos que a vida em contou - Livro de memórias. São Paulo. Life editora. 2018. p. 63 e 65.

Barravento. Direção de Glauber Rocha. Lançamento em 1969 na França. Produtora Iglu Filmes Produção: Rex Schindler, Braga Netto 1962. (1h20m).

Benjamim, Walter. A obra de arte na era de sua reprodutibilidade técnica. Porto Alegre. Zouk. 2012.

Cardoso. Maurício. O cinema tricontinental de Glauber Rocha: política, estética e revolução (1969 - 1974). Tese de doutorado pela Universidade de São Paulo, Faculdade de Filosofia, Letras e ciências Humanas. Departamento de História. São Paulo - 2007. Disponível em: < file://C:/Users/ usuario/Downloads/Tese_mauricio_cardoso.pdf > acesso em 17 maio 2017.

Carvalho. Noel dos Santos; Domingues, Petrônio. A representação do negro em dois manifestos do cinema brasileiro. Revista Estudos avançados Estud. av. vol.31 no .89 São Paulo Jan./Abr. 2017. Disponível em: https://www.scielo.br/scielo.php?script=sci_arttext\&pi$\mathrm{d}=$ S0103-40142017000100377> Acesso em 30 de abr. 2020.

Césaire, Aimé. Discurso sobre o colonialismo. Ed. Cadernos para o diálogo. Porto. 1971, p. 5 e 6 . 
Cinco Vezes Favela. Direção: Marcos Farias, Miguel Borges, Cacá Diegues, Joaquim Pedro de Andrade, Leon Hirszman. Produtora o Centro Popular de Cultura (CPC) da União Nacional dos Estudantes. 1962. (92min).

Deleuze, Gilles. Cinema: a imagem-movimento. Tradução Stella Sena. São Paulo. Editora Brasiliense, 1983.

Cinema I: A imagem-movimento. São Paulo, SP: Brasiliense, 1985.

O Dragão da Maldade Contra o Santo Guerreiro. Direção: Glauber Rocha. Produção Mapa Filmes. 1969 (1h40min).

Duarte, Rosália. Cinema \& Educação. Belo Horizonte: Autêntica, 2002.

Gerber, Raquel. Glauber Rocha e a experiência inacabada do cinema novo, Coleção cinema, v.1, Rio de Janeiro. Paz e Terra, 1977.

Holanda, Sérgio Buarque de. Raízes do Brasil. Companhia das letras. 1999, São Paulo, (Trabalho original publicado em 1936).

Instituto Ethos. Perfil social, racial e de gênero das 500 maiores empresas do Brasil e suas ações afirmativas / Instituto Ethos e Banco Interamericano de Desenvolvimento. 2016. Disponível em: <https://www.ethos.org.br/wp-content/uploads/2016/05/Perfil_Social_Tacial_Genero_500empresas.pdf> Acesso em 14 set. 2019.

Leão De Sete Cabeças. Direção: Glauber Rocha. Paris: Polifilm; Claude Antoine Filmes, 1971(01:03 Hrs.).

Marx, Karl. Engels, Friedrich. Manifesto do Partido Comunista. Ed. Ridendo Castigat More. Edição eletrônica. eBooks Brasil.com Disponível em: < http://www.ebooksbrasil.org/adobeebook/ manifestocomunista.pdf> Acesso em: 28 ago.2017.

O Menelick. Nabor Jr. é fundador-diretor. Colaboração Akins Kinte. Na sala com Ari. Julho 2014. Disponível em: http://www.omenelick2ato.com/fotografia-e-cinema/na-sala-com-ari>. Acesso em: 30 abr. 2020.

Morais-Alexandre, Paulo J. Estereótipo na criação de uma dramaturgia para o figurino do negro, e não só, no cinema. In: 15ª Mostra Internacional do Cinema Negro. Celso Luiz Prudente (Org.). $1^{\text {a }}$. ed. São Paulo: Sesc, 2019. 148p

Oliveira, F. R.; Prudente C. L. A lusofonia de horizontalidade da imagem do ibero-ásio-afro-amerindio versus a verticalidade da hegemonia imagética do euro-hétero-macho-autoritário: a dimensão pedagógica do cinema negro posto em questão. $1^{\mathrm{a}}$ ed.Portugal: AULP, 2017, v. 1, p. 107116.

Palma, Ana. Monteiro Lobato e a origem do Jeca Tatu. Invivo. Fiocruz Fundação Oswaldo Cruz. Publicada em 29 de Nov. 2009. Disponível em: <http://www.invivo.fiocruz.br/cgi/cgilua.exe/ sys/start.htm?infoid=1035\&sid=7> Acesso em 03 nov. 2019

Por quê a Eritreia?. Direção: Ari Cândido. Produção: Ari Cândido. 1978 
Prudente, Celso Luiz. A dimensão pedagógica do Cinema Negro: a imagem de afirmação positiva do íbero-ásio-afro-ameríndio. Revista Extraprensa, v. 13, p. 5-305, 2019a. Disponível em: $<$ https://www.revistas.usp.br/extraprensa/issue/view/11392> acesso em: 01 maio 2020.

; Silva, D. C. A dimensão pedagógica do cinema negro aspectos de uma arte para a afirmação ontológica do negro brasileiro: O olhar de Celso Prudente. $2^{\mathrm{a}}$. ed. São Paulo: Anita Garibaldi, 2019b. 195p.

. A dimensão pedagógica do cinema negro. Avanca Cinema 2018 Conferência Internacional de Cinema, arte, tecnologia e comunicação. Capítulo II Cinema. 1ed.Avanca Portugal: Cine-clube Avanca, 2018, v. 1, p. 2-794.

Ramos, Fernão. História do cinema brasileiro, São Paulo, Art. Editora, 1960.

Rio 40 Graus. Direção: Nelson Pereira dos Santos, Associação Brasileira de Críticos de Cinema (Abracine). 1955. (100min).

Schwarcz, Lilia M. Sérgio Buarque de Holanda e essa tal de "cordialidade” Ide (São Paulo) v.31 n.146 São Paulo jun. 2008. Disponível em: http://pepsic.bvsalud.org/scielo.php?script=sci_arttext\&pid=S0101-31062008000100015 $>$ Acesso em: 01 maio 2020.

Vandré, Geraldo. Para não dizer que não falei das flores. Letras. Legendado por Rebeca e Jonas.. Composição de Geraldo Vandré. Disponível em: https://www.letras.mus.br/geraldo-vandre/46168/> Acesso em 12 set. 2019.

Data receção: 23/01/2020

Data aprovação: 02/04/2020 